\title{
Grape seed proanthocyanidins protect cardiomyocytes against hypoxia/reoxygenation injury by attenuating endoplasmic reticulum stress through PERK/eIF2 $\alpha$ pathway
}

\author{
XIN WANG, DALIN JIA, JUNCHENG ZHANG and WEI WANG \\ Department of Cardiology, The First Affiliated Hospital of China Medical University, Shenyang, Liaoning 110001, P.R. China
}

Received October 8, 2016; Accepted August 23, 2017

DOI: $10.3892 / \mathrm{mmr} .2017 .7756$

\begin{abstract}
The aim of the present study was to observe the protective effect of grape seed proanthocyanidins (GSPs) against endoplasmic reticulum (ER) stress-mediated apoptosis caused by hypoxia/reoxygenation $(H / R)$ injury in H9C2 cardiomyocytes along with its potential mechanisms. H9C2 cardiomyocytes underwent hypoxia for $3 \mathrm{~h}$ followed by reoxygenation for $3 \mathrm{~h}$. Different doses of GSPs $(50,100$ and $200 \mu \mathrm{g} / \mathrm{ml}$ ) were administered $30 \mathrm{~min}$ before hypoxia. Cell viability was assessed, as well as lactic dehydrogenase (LDH) activity, cell apoptosis rate, expression levels of glucose-regulated protein 78 (GRP78), C/EBP-homologous protein (CHOP), protein kinase RNA-like ER kinase (PERK), and eukaryotic translation initiation factor-2 (eIF2 $\alpha$ ) mRNA and protein. The results revealed that GSPs improved cell viability, reduced LDH activity and reduced the apoptosis rate in cells subjected to $H / R$, and that the protective effect was most significant when $100 \mu \mathrm{g} / \mathrm{ml}$ in GSPs was administered. GSPs treatment also decreased mRNA and protein expression of GRP78, CHOP, eIF2 $\alpha$ and the level of the phosphorylated form of PERK. Furthermore, GSPs displayed a similar protective effect to that of established ER stress inhibitor 4-phenyl butyric acid. In conclusion, the findings of this study suggest that GSPs may protect H9C2 cardiomyocytes from H/R injury by decreasing ER stress-mediated apoptosis through the suppression of the PERK/eIF2 $\alpha$ signaling pathway.
\end{abstract}

\section{Introduction}

Reperfusion therapy performed as early as possible is a key strategy for the treatment of ischemic heart disease; however, it may cause myocardial ischemia/reperfusion (I/R)

Correspondence to: Professor Dalin Jia, Department of Cardiology, The First Affiliated Hospital of China Medical University, 155 North Nanjing Street, Heping, Shenyang, Liaoning 110001, P.R. China E-mail: jiadalincmu@163.com

Key words: grape seed proanthocyanidins, hypoxia/reoxygenation, endoplasmic reticulum stress, protein kinase RNA-like ER kinase, H9C2 cardiomyocytes injury, leading to myocardial dysfunction, and even cardiomyocytes apoptosis $(1,2)$. Effective measures for the prevention of myocardial I/R injury have come under heated debate (3), including various ischemic pre-conditionings or post-conditionings from pharmacological and mechanical methods (4,5). However, the efficiency of these therapeutic agents for limiting myocardial I/R injury has been questioned due to the complicated mechanisms involved in $\mathrm{I} / \mathrm{R}$ injury $(6,7)$. At present, increasing studies have suggested that endoplasmic reticulum (ER) stress has an important role in the pathological process of I/R injury (8).

ER stress refers to a pathological process in which ER homeostasis is affected and physical function is disordered due to exposure to various harmful stimuli, such as intracellular $\mathrm{Ca}^{2+}$ overload, ATP deprivation and hypoxia; which may cause an accumulation of misfolded or unfolded proteins in the ER lumen (9). ER stress results in an increased expression of the glucose-regulated protein 78 (GRP78), and increased rate of activation of inositol-requiring protein-1, protein kinase RNA-like ER kinase (PERK), and activating transcription factor-6 (ATF6) pathways that regulate accumulation of unfolded proteins in order to protect the cell from damage $(10,11)$. In cases of prolonged or excessive ER stress, ER-associated apoptosis occurs following the activation of the $\mathrm{C} / \mathrm{EBP}$-homologous protein (CHOP), c-Jun-N-terminal protein kinase (JNK) and caspase-12 apoptosis pathways $(12,13)$. The CHOP pathway is an important branch of ER stress apoptosis pathways. When ER stress occurs, increased PERK activation may phosphorylate eukaryotic translation initiation factor-2 (eIF2 $\alpha$ ) for the upregulation of the PERK/eIF2 $\alpha$ signaling pathway in order to increase the expression of the downstream target, CHOP.

Proanthocyanidins are a series of bioavailable polyphenol flavonoids compounds derived from vegetables and fruits, containing dimers, trimers and other oligomers of catechin and epicatechin and their glallic acid esters. Grape seed proanthocyanidins (GSPs) are potent antioxidants that possess a greater ability in the scavenging free radicals than that of vitamin $\mathrm{C}$, vitamin $\mathrm{E}$ or $\beta$-carotene (14). GSPs provide various protective effects, such as anti-inflammatory (15), anti-oxidant, anti-apoptotic (16), antitumor (17) and cardioprotective activities (18). However, the effect of GSPs on hypoxia/reoxygenation (H/R) injury involving PERK-CHOP-mediated ER stress-associated apoptosis has not been investigated thus far. 
Therefore, in this study, the protective effects of GSPs subjected to $\mathrm{H} / \mathrm{R}$ injury were investigated as well as the role of ER stress-associated apoptosis in $\mathrm{H} 9 \mathrm{C} 2$ cardiomyocytes through the PERK/eIF2 $\alpha$ signaling pathway under varying administered concentrations of GSPs.

\section{Materials and methods}

Reagents. The following reagents were used: GSPs (Aladdin Co., Ltd., Shanghai, China); H9C2 cardiomyocytes (Chinese Academy of Sciences Cell Bank, Shanghai, China); Dulbecco's modified Eagle's medium (DMEM; Gibco; Thermo Fisher Scientific, Inc., Waltham, MA, USA); fetal bovine serum (FBS; HyClone, Logan, UT, USA); dimethyl sulfoxide (DMSO), 4-phenyl butyric acid (4-PBA) and MTT (Sigma-Aldrich; Merck KGaA, Darmstadt, Germany); lactate dehydrogenase (LDH) Release assay kit (Nanjing Jiancheng Bioengineering Institute, Nanjing, China). The Annexin V/Propidium Iodide Apoptosis Detection kit; Total Protein Extraction kit [WLA019, including radioimmunoprecipitation assay (RIPA) lysis buffer and phenylmethylsulfonyl fluoride], enhanced chemiluminescence solution (WLA003) and antibodies against GRP78 (1:500; WL00621), CHOP (1:500; WL00621), eIF2 $\alpha$ (1:500; WL01909) and $\beta$-actin (1:1,000; WL01845) were all from Wanleibio Co., Ltd. (Shenyang, China). Antibodies against PERK (1:500; bs-2469R), phosphorylated PERK (p-PERK; 1:1,000, bs-3330R) and, phosphorylated eIF2 $\alpha$ (p-eIF2 $\alpha ; 1: 500$; bs-4842R) were all from BIOSS (Beijing, China). The RNA Extraction kit (RP1201), Super M-MLV reverse transcriptase (PR6502) and 2X Power Taq PCR MasterMix (PR1702) were from BioTeke Corporation (Beijing, China). SYBR-Green (SY1020) was from Beijing Solarbio Science and Technology Co., Ltd. (Beijing, China) and the primers were from Sangon Biotech Co., Ltd. (Shanghai, China).

$H 9 C 2$ cardiomyocyte culture and $H / R$. H9C2 cardiomyocytes were cultured in DMEM containing 10\% FBS in 6-well plates and maintained at a constant humidity in an incubator containing $5 \% \mathrm{CO}_{2}$ at $37^{\circ} \mathrm{C}$ for $24 \mathrm{~h}$. The cardiomyocyte status was then observed and the cells continued to undergo culture post-cleaning with $2 \mathrm{ml}$ PBS and replacement of $2 \mathrm{ml}$ fresh culture fluid. When cultured to $90 \%$ confluence, $\mathrm{H} 9 \mathrm{C} 2$ cardiomyocytes were incubated in 96-well plates at a density of $1 \times 10^{4}$ cells/well for further experiments.

The $H / R$ process was modified from a previously described method (19). Medium was replaced with DMEM without glucose and transferred into a tri-gas incubator containing $95 \% \mathrm{~N}_{2}$ and $5 \% \mathrm{CO}_{2}$ at $37^{\circ} \mathrm{C}$ to mimic hypoxia for $3 \mathrm{~h}$. The medium was then changed to normal DMEM and cells were cultured in a regular incubator $\left(37^{\circ} \mathrm{C}, 5 \% \mathrm{CO}_{2}\right)$ for $3 \mathrm{~h}$ to mimic reoxygenation.

Experimental design. The cardiomyocytes were divided into six groups and cultured in 6-well or 96-well culture plates at a density of $1 \times 10^{4} / \mathrm{ml}$. The groups were as follows: i) Control group, cardiomyocytes cultured with normal DMEM medium under normoxic conditions throughout the duration of the experiments; ii) $H / R$ group, cardiomyocytes cultured for $3 \mathrm{~h}$ in hypoxic conditions and then $3 \mathrm{~h}$ in under normal conditions (H3 h/R3 h); iii-v) H/R + GSPL/M/H groups, cardiomyocytes were cultured in DMEM medium containing GSPs of different concentrations (50,100 and $200 \mu \mathrm{g} / \mathrm{ml}$, respectively) under normal conditions for 30 min followed by H3 h/R3 h; vi) $\mathrm{H} / \mathrm{R}+4-\mathrm{PBA}$ group, cardiomyocytes were pretreated with $1 \mathrm{mM} 4$-PBA for 30 min followed by $\mathrm{H} 3 \mathrm{~h} / \mathrm{R} 3 \mathrm{~h}$.

MTT assay of cardiomyocyte viability analysis. Cell viability was determined by the MTT assay. MTT $(5 \mathrm{mg} / \mathrm{ml})$ was added to cardiomyocytes from each group after designated disposal and incubated at $37^{\circ} \mathrm{C}$ for $4 \mathrm{~h}$. The supernatant extract was then removed and $200 \mu 1$ DMSO was then added in order to dissolve the formazan crystals. The absorbance value at $490 \mathrm{~nm}$ using a microplate reader (BioTek Instruments, Inc., Winooski, VT, USA) was then determined.

Detection of LDH activity. LDH activity was detected using the LDH Release assay kit. Supernatant $(20 \mu \mathrm{l})$ was obtained from each experimental group and mixed with $25 \mu \mathrm{l}$ 2,4-dinitrobenzene hydrazine in a $37^{\circ} \mathrm{C}$ bath for $15 \mathrm{~min}$, and then mixed with $250 \mu 10.4 \mathrm{M} \mathrm{NaOH}$ at room temperature for $5 \mathrm{~min}$ before determining the absorbance value at $490 \mathrm{~nm}$ on the aforementioned microplate reader.

Flow cytometric measurement of apoptosis. The cell apoptosis and necrosis ratio was measured using the Annexin V/Propidium Iodide kit for flow cytometric analysis. Cardiomyocytes were collected, centrifuged and washed with PBS, and then resuspended in binding buffer. Annexin V-Fluorescein isothiocyanate (FITC) $(5 \mu \mathrm{l})$ and propidium iodide $(10 \mu \mathrm{l})$ were then added to each sample and the samples were then incubated for $15 \mathrm{~min}$ in the dark at room temperature. Results were analyzed using BD Accuri C6 (BD Biosciences, Franklin Lakes, NJ, USA) and presented as scatterplots, with the lower right quadrant representing early apoptotic cells and upper right quadrant representing late apoptotic and necrotic cells.

Morphologic observation under electron microscope. Cardiomyocytes were collected from each group for analysis by electron microscopy. Each sample was immersed in $2.5 \%$ glutaraldehyde for $>2 \mathrm{~h}$. Following serial dehydration, samples were embedded and polymerized in Epon-812 sequentially at $35^{\circ} \mathrm{C}, 40^{\circ} \mathrm{C}$ and $60^{\circ} \mathrm{C}(24 \mathrm{~h}$ each), for a total of $72 \mathrm{~h}$. Following this, 50-70 $\mathrm{nm}$ microsections of the samples were cut using a LEICA EM UC7 ultramicrotome (Leica Microsystems, Inc., Buffalo Grove, IL, USA) followed by staining in acetic acid oil and lead citrate (5 drops for $30 \mathrm{~min}$ respectively). The ultrastructure was observed under magnification $\times 10,000$ to $\times 20,000$.

Reverse transcription-quantitative polymerase chain reaction (RT-qPCR). The RNA samples were extracted using the RNA Extraction kit, and RT of the extracted RNA samples was performed on an Exicycler ${ }^{\mathrm{TM}} 96$ (Bioneer Corporation, Dajeon, Korea) to obtain appropriate cDNA as follows: RNA samples were heated at $70^{\circ} \mathrm{C}$ for $5 \mathrm{~min}$ before cooling rapidly for $2 \mathrm{~min}$; M-MLV reverse transcriptase was added and the samples were placed in a water bath at $25^{\circ} \mathrm{C}$ for $10 \mathrm{~min}, 42^{\circ} \mathrm{C}$ for $50 \mathrm{~min}$ and then $95^{\circ} \mathrm{C}$ for $5 \mathrm{~min}$ to terminate the reaction. The qPCR reaction comprised of $1 \mu \mathrm{l}$ cDNA sample, $0.5 \mu \mathrm{l}$ 5' and 3' primers $(10 \mu \mathrm{M}), 9.7 \mu 1$ PCR Mastermix, $0.3 \mu \mathrm{l}$ 
SYBR-Green and $8 \mu 1 \mathrm{ddH}_{2} \mathrm{O}$ in total volume of $20 \mu \mathrm{l}$. The cDNA was amplified under the following conditions: $95^{\circ} \mathrm{C}$ for $10 \mathrm{~min}, 40$ cycles of $95^{\circ} \mathrm{C}$ for $10 \mathrm{sec}, 60^{\circ} \mathrm{C}$ for $20 \mathrm{sec}, 72^{\circ} \mathrm{C}$ for $30 \mathrm{sec}$ and $4^{\circ} \mathrm{C}$ for $5 \mathrm{~min}$. The oligonucleotide primer sets were as follows: GRP78 forward, 5'-GATAATCAGCCC ACCGTAA-3' and reverse, 5'-TTGTTTCCTGTCCCTTTG T-3'; CHOP forward, 5'-CTCTGCCTTTCGCCTTTGA-3' and reverse, 5'-GCTTTGGGAGGTGCTTGTG-3'; PERK forward, 5'-TTAGCAAGCCAGAGGTGTT and reverse, 5'-GAGCCC GTATGTGGTCAG-3'; eIF2 $\alpha$ forward, 5'-TCCACCCAGGTA TGTGAT-3' and reverse, 5'-TTTGGCTTCCATTTCTTC-3'; $\beta$-actin forward, 5'-GGAGATTACTGCCCTGGCTCCTAG C-3' and reverse, 5'-GGCCGGACTCATCGTACTCCTGCT T-3'. Data obtained were analyzed using the relative gene expression $2^{-\Delta \Delta C q}$ method (20).

Western blot. Cardiomyocyte protein was extracted with RIPA lysis buffer containing $1 \%$ phenylmethylsulfonyl fluoride. Bicinchoninic acid assay was used to measure protein concentration. Protein $(40 \mu \mathrm{g})$ from each sample was separated using SDS-PAGE (8-13\% polyacrylamide), transferred to a polyvinylidene fluoride membrane and blocked with 5\% non-fat milk in Tris-buffered saline containing $0.05 \%$ Tween-20. Following this, the membranes were incubated with either primary or $\beta$-actin antibodies overnight at $4^{\circ} \mathrm{C}$. The membranes were then washed and incubated with secondary horseradish peroxidase-conjugated $\mathrm{IgG}$ antibodies for $45 \mathrm{~min}$ at $37^{\circ} \mathrm{C}$. Enhanced chemiluminescence was then carried out after a 30 min wash. The films were then scanned and the densities of the protein bands were analyzed using Image $\mathbf{J}$ software (GraphPad Software, Inc., La Jolla, CA, USA).

Statistical analysis. All data are presented as the mean \pm standard error. One-way analysis of variance with Student-Newman-Keuls post hoc test was used for analysis using SPSS version 17.0 software. $\mathrm{P}<0.05$ was considered to indicate a statistically significant difference.

\section{Results}

GSPs improves cell viability in cardiomyocytes subjected to $H / R$. Compared with the control group, the levels of cell viability were dramatically decreased in the H/R group. Compared with the $H / R$ group, the levels of cell viability were increased in the H/R + GSPM/H group, whereas the levels of cell viability in the $\mathrm{H} / \mathrm{R}+\mathrm{GSPL}$ group showed no significant change compared with the $\mathrm{H} / \mathrm{R}$ group $(\mathrm{P}=0.408)$. Cell viability in the GSPs $(100 \mu \mathrm{g} / \mathrm{ml})$ pretreatment group was higher than that in the GSPs $(50$ and $200 \mu \mathrm{g} / \mathrm{ml})$ pretreatment groups. Compared with the group pretreated with 4-PBA, the groups pretreated with GSPs (100 and $200 \mu \mathrm{g} / \mathrm{ml}$ ) had no differences in cell viability (Fig. 1). These results therefore suggest that treatment with GSPs leads to improved cell viability and that $100 \mu \mathrm{g} / \mathrm{ml}$ GSPs pretreatment provided the optimal effect.

GSPs reduce LDH activity in cardiomyocytes subjected to $H / R$. Analysis of the extent of cellular release of LDH is shown in Fig. 2. A significant increase of LDH activity was observed in the $\mathrm{H} / \mathrm{R}$ group compared with that of the control group $(289.34 \pm 48.03$ vs. $129.04 \pm 11.62$; $\mathrm{P}<0.01)$. Pretreatment with

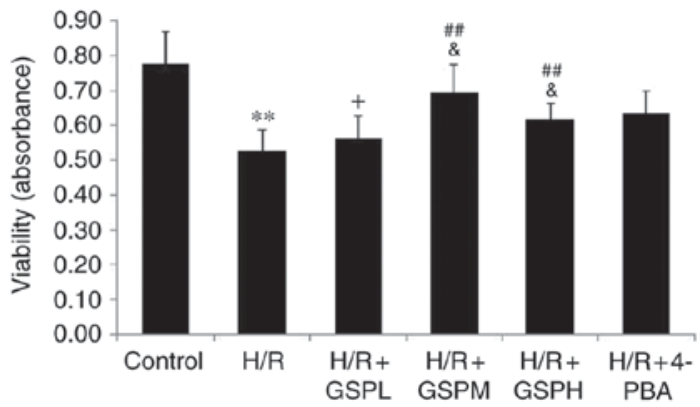

Figure 1. GSPs improved cell viability in cardiomyocytes subjected to H/R. H9C2 cardiomyocyte viability was evaluated using MTT. Data are expressed as the mean \pm standard deviation; $n=5$. $^{* *} \mathrm{P}<0.01$ vs. the control group, ${ }^{+} \mathrm{P}>0.05$ and ${ }^{\# \#} \mathrm{P}<0.01$ vs. the $\mathrm{H} / \mathrm{R}$ group, ${ }^{\&} \mathrm{P}>0.05$ vs. the $\mathrm{H} / \mathrm{R}+4-\mathrm{PBA}$ group. GSP, grape seed proanthocyanidins; GSPL, GSP low (50 $\mu \mathrm{g} / \mathrm{ml})$; GSPM, GSP medium (100 $\mu \mathrm{g} / \mathrm{ml})$; GSPH, GSP high (200 $\mu \mathrm{g} / \mathrm{ml}) ; \mathrm{H} / \mathrm{R}$, hypoxia/reoxygenation; 4-PBA, 4-phenylbutyrate.

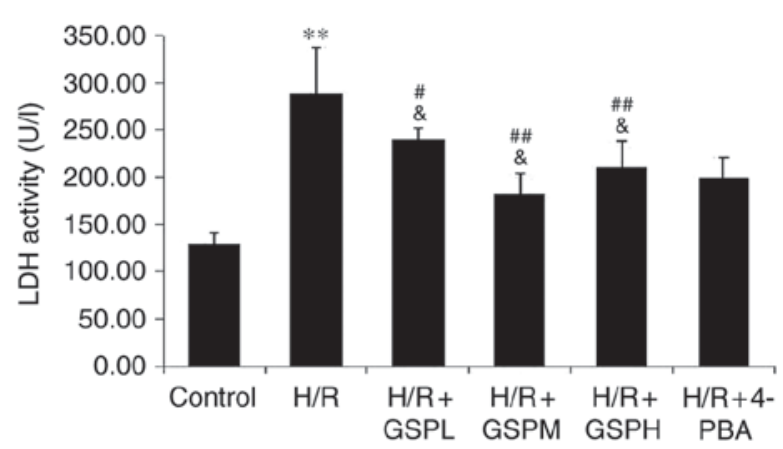

Figure 2. GSPs reduced LDH activity in cardiomyocytes subjected to H/R. Data were expressed as mean \pm standard deviation; $n=5{ }^{* *} \mathrm{P}<0.01$ vs. the control group, ${ }^{\#} \mathrm{P}<0.05$ and ${ }^{\# \#} \mathrm{P}<0.01$ vs. the $\mathrm{H} / \mathrm{R}$ group, ${ }^{\circledR} \mathrm{P}>0.05$ vs. the H/R + group. GSP, grape seed proanthocyanidins; GSPL, GSP low (50 $\mu \mathrm{g} / \mathrm{ml})$; GSPM, GSP medium (100 $\mu \mathrm{g} / \mathrm{ml})$; GSPH, GSP high (200 $\mu \mathrm{g} / \mathrm{ml}) ; \mathrm{H} / \mathrm{R}$, hypoxia/reoxygenation; $\mathrm{LDH}$, lactate dehydrogenase; 4-PBA, 4-phenylbutyrate.

GSPs was demonstrated to significantly reduce LDH activity $(240.44 \pm 11.19,182.35 \pm 21.68,210.30 \pm 27.93$ vs. H/R). No significant differences were observed among the GSPs-treated groups and 4-PBA pretreatment $(200.00 \pm 21.68$ vs. GSPs pretreatment; $\mathrm{P}>0.05$ ).

GSPs attenuates cell apoptosis ratio in cardiomyocytes subjected to $H / R$. Cell apoptosis was also assessed using Annexin-V FITC/propidium iodide staining (Fig. 3). The apoptosis rate was markedly increased in the H/R group compared to that of the control group $(24.01 \pm 1.21$ vs. $0.35 \pm 0.02$; $\mathrm{P}<0.01$ ). Additionally, pretreatment with GSPs significantly decreased levels of apoptotic and necrotic cells caused by $H / R$ (15.31 $\pm 1.09,9.23 \pm 0.81,12.62 \pm 1.23$ vs. $24.01 \pm 1.21$; $\mathrm{P}<0.01$ ). The GSPs $(100 \mu \mathrm{g} / \mathrm{ml})$ and 4-PBA treatment groups displayed similar levels of apoptosis $(9.23 \pm 0.81$ vs. $10.76 \pm 1.28, \mathrm{P}>0.05)$, while 50 and $200 \mu \mathrm{g} / \mathrm{ml} \mathrm{GSP}$ treatment displayed higher apoptosis rates than that of 4-PBA treatment $(\mathrm{P}<0.05)$. These results suggest that GSPs may have an anti-apoptosis function and work optimally at a concentration of $100 \mu \mathrm{g} / \mathrm{ml}$.

Ultrastructural morphology by electron microscopy. The control group cells displayed normal cytomembranes, nuclei, 
A
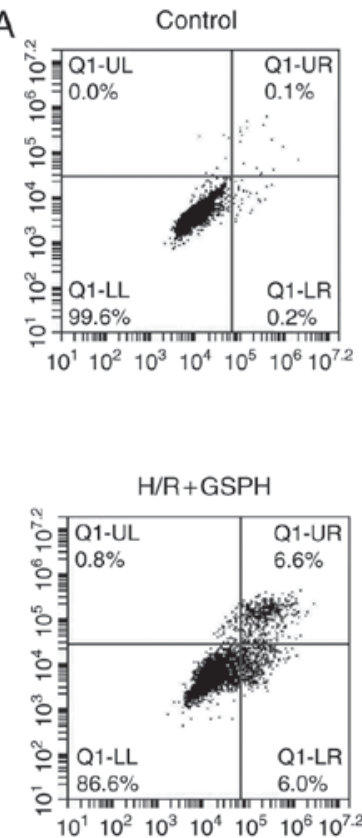
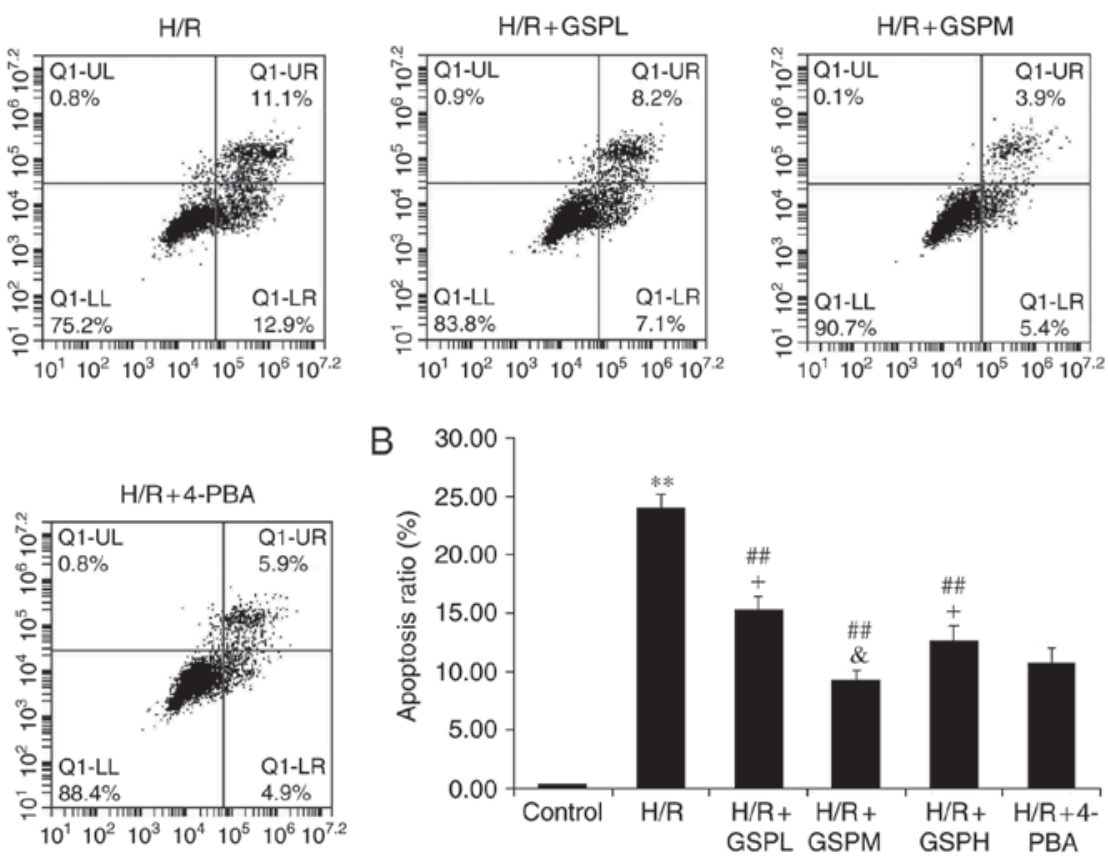

Figure 3. GSPs attenuated cell apoptosis ratio in cardiomyocytes subjected to H/R. Flow cytometry results were displayed as quantitative assessment of cell apoptosis (A) and (B) quantitative bar graphs. Data were expressed as the mean \pm standard deviation; $\mathrm{n}=5$. ${ }^{* *} \mathrm{P}<0.01 \mathrm{vs}$. the control group, ${ }^{\sharp \#} \mathrm{P}<0.01 \mathrm{vs}$. the $\mathrm{H} / \mathrm{R}$ group, ${ }^{\circledR} \mathrm{P}>0.05$ and ${ }^{+} \mathrm{P}<0.05$ vs. the H/R+4-PBA group. GSP, grape seed proanthocyanidins; GSPL, GSP low (50 $\left.\mu \mathrm{g} / \mathrm{ml}\right) ; \mathrm{GSPM}$, GSP medium (100 $\left.\mu \mathrm{g} / \mathrm{ml}\right)$; GSPH, GSP high $(200 \mu \mathrm{g} / \mathrm{ml}) ; \mathrm{H} / \mathrm{R}$, hypoxia/reoxygenation; LL, lower left quadrant; LR, lower right quadrant; UL, upper left quadrant; UR, upper right quadrant; 4-PBA, 4-phenylbutyrate.

mitochondria, ER and other cellular structures (Fig. 4). However, the H/R group cells showed obvious signs of cellular damage demonstrated by nuclear membrane defects, swelling and vacuolization of mitochondria, and dilatation of the ER. Additionally, a number of apoptotic bodies were visible in the imaged H/R cells. The groups that underwent pretreatment with GSPs displayed complete nuclear membranes and increasing numbers of normal mitochondria and ER, whereas the levels of apoptotic bodies were decreased. Similar results to those displayed by the GSPs pretreatment groups were obtained in the 4-PBA group.

Relative quantitative expression of GRP78, CHOP, PERK and IF $2 \alpha$ mRNA). The relative expression levels of GRP78, CHOP and eIF $2 \alpha$ mRNA were increased notably following $\mathrm{H} / \mathrm{R}$ treatment compared with the control group $(\mathrm{P}<0.01)$ and decreased following GSPs treatment $(\mathrm{P}<0.01)$ as demonstrated in Fig. 5. Furthermore, the mRNA expression levels of GRP78, CHOP and eIF $2 \alpha$ were consistent between the H/R + GSPM group and the $\mathrm{H} / \mathrm{R}+4-\mathrm{PBA}$ group $(\mathrm{P}<0.05)$. Additionally, no difference in the level of CHOP mRNA was observed between the H/R + GSPH group and H/R + 4-PBA group. The expression levels of PERK mRNA remained unchanged among all groups $(\mathrm{P}>0.05)$.

Protein expression of GRP78, CHOP, PERK and eIF $2 \alpha$. As shown in Fig. 6, the protein expression levels of GRP78, CHOP, p-PERK and p-eIF $2 \alpha$ were all significantly elevated in cardiomyocytes exposed to $\mathrm{H} / \mathrm{R}(\mathrm{P}<0.01)$. Concurrently, the protein expression levels were downregulated in the H/R + GSP groups $(\mathrm{P}<0.01)$. There was no apparent change in protein expression levels between $\mathrm{H} / \mathrm{R}+\mathrm{GSPM}$ group and $\mathrm{H} / \mathrm{R}+4$-PBA group
( $\mathrm{P}>0.05)$, whereas the $\mathrm{H} / \mathrm{R}+\mathrm{GSPL} / \mathrm{H}$ groups displayed higher protein expression levels than the $\mathrm{H} / \mathrm{R}+4$-PBA group with the exception of $\mathrm{CHOP}$ protein expression. The results were in accordance with the results of the mRNA expression levels, suggesting that GSPs inhibit ER stress and the PERK/eIF2 $\alpha$ pathway, and have a similar function to ER stress-specific inhibitor 4-PBA.

\section{Discussion}

The findings of this study suggest that GSPs exhibits a significant protective effect against H/R injury in H9C2 cardiomyocytes in a non-dose dependent manner and at an optimal concentration of $100 \mu \mathrm{g} / \mathrm{ml}$. A possible mechanism of protection appears to be dependent on the attenuation of ER stress-mediated apoptosis as well as downregulation of PERK-eIF2 $\alpha$-CHOP pathway activation.

Myocardial I/R injury is a complex pathophysiological process that heavily involves various apoptosis signaling pathways (21). Previous studies have reported that mitochondrial-mediated apoptosis and death receptor pathways contributed to the myocardial I/R injury process. Previously, ER stress has been verified as the third largest apoptosis pathway, and has an important role in I/R injury (22). H/R is an in vitro cell culture model for simulation of $\mathrm{I} / \mathrm{R}$.

Considering that the presence of the LDH enzyme is specific to myocardial cytoplasm, its increasing expression level is an important indicator of H/R injury (23). In the current study, increased LDH activity, apoptosis rate, decreased cell viability as well as morphological changes in the H/R group indicated severe injury mediated by $\mathrm{H} / \mathrm{R}$. The administration of GSPs reduced the level of $\mathrm{LDH}$ activity and the apoptosis 

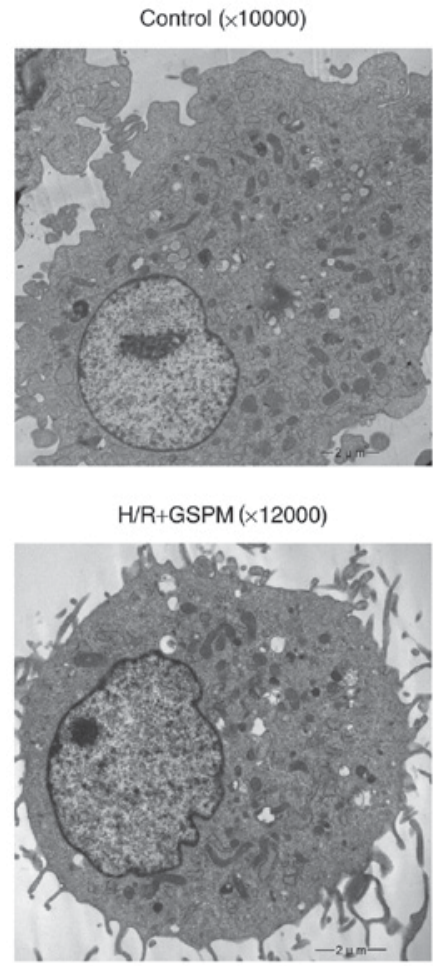

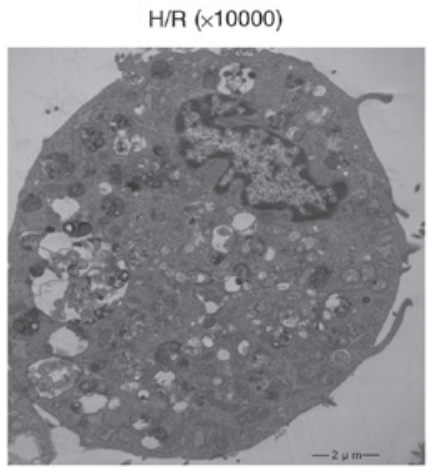

H/R+GSPM $(\times 20000)$

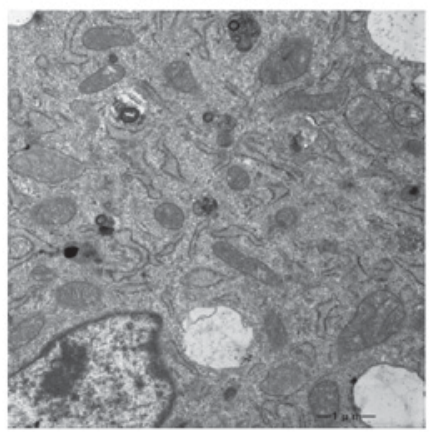

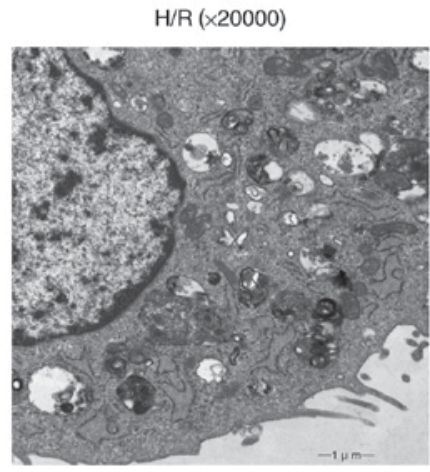

H/R+4-PBA $(\times 10000)$

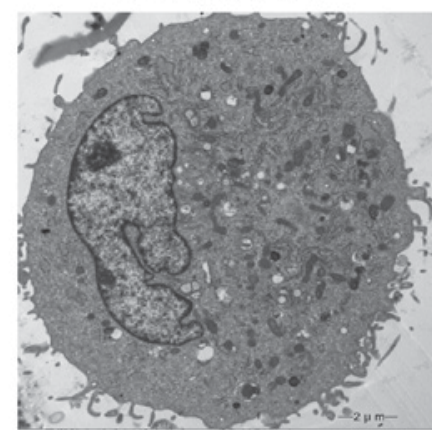

Figure 4. Morphological observation on cardiomyocytes from the normal, H/R and GSPs or 4-PBA treatment groups. The control group exhibited normal cardiomyocyte structure; H/R induced severe nuclear membrane defects, swelling and vacuolization of mitochondria, and dilatation of endoplasmic reticulum as well as the appearance of many apoptotic bodies; GSPs administration improved the condition; 4-PBA administration displayed similar changes to the administration of GSPs. H/R, hypoxia/reoxygenation; GSP, grape seed proanthocyanidins; GSPM, GSP medium (100 $\mu \mathrm{g} / \mathrm{ml}) ;$ 4-PBA, 4-phenylbutyrate.
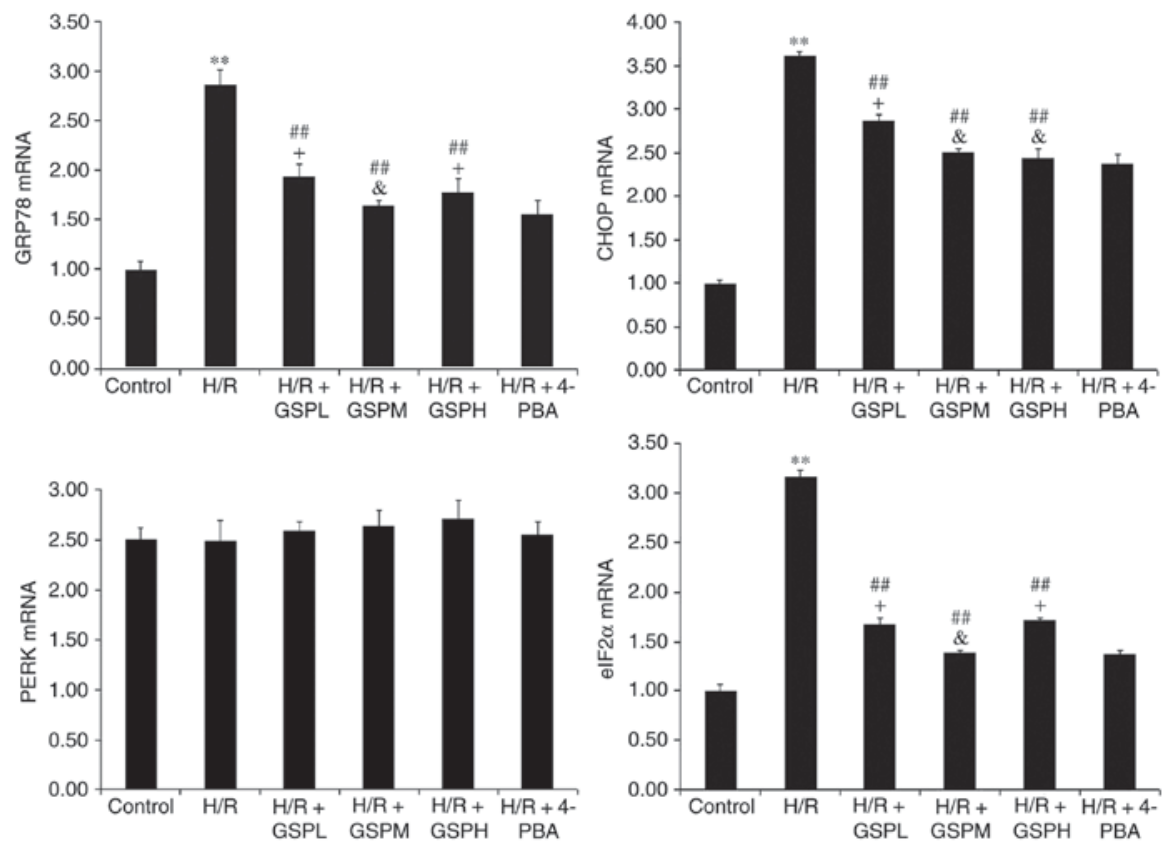

Figure 5. GSPs inhibited mRNA expression of GRP78, CHOP and eIF2 $\alpha$ in cardiomyocytes subjected to H/R. The relative quantitative expression levels of GRP78, CHOP, PERK and eIF2 $\alpha$ detected by reverse transcription-quantitative polymerase chain reaction were displayed as fold change compared with that in the control group by quantitative bar graphs. Data are expressed as mean \pm standard deviation; $n=3$. ${ }^{* *} \mathrm{P}<0.01$ vs. the control group, ${ }^{\# \#} \mathrm{P}<0.01$ vs. the $\mathrm{H} / \mathrm{R}$ group, ${ }^{\&} \mathrm{P}>0.05$ and ${ }^{+} \mathrm{P}<0.05$ vs. the $\mathrm{H} / \mathrm{R}+4$-PBA group. GPR78, glucose-regulated protein 78; CHOP, C/EBP-homologous protein; eIF2 $\alpha$, eukaryotic translation initiation factor-2 $\alpha$; GSP, grape seed proanthocyanidins; GSPL, GSP low (50 $\mu \mathrm{g} / \mathrm{ml}) ; \mathrm{GSPM}, \mathrm{GSP}$ medium (100 $\mu \mathrm{g} / \mathrm{ml}) ; \mathrm{GSPH}, \mathrm{GSP}$ high (200 $\mu \mathrm{g} / \mathrm{ml}) ; \mathrm{H} / \mathrm{R}$, hypoxia/reoxygenation; PERK, protein kinase RNA-like endoplasmic reticulum kinase; 4-PBA, 4-phenylbutyrate.

rate, as well as improving cell viability and morphological changes, which reflected the protective effect of GSPs on cardiomyocytes subjected to H/R. In addition, the effect of
GSPs was dose-dependent, as the administration of $100 \mu \mathrm{g} / \mathrm{ml}$ GSPs treatment exhibited a greater protective effect than that of the 50 or $200 \mu \mathrm{g} / \mathrm{ml}$ groups. 

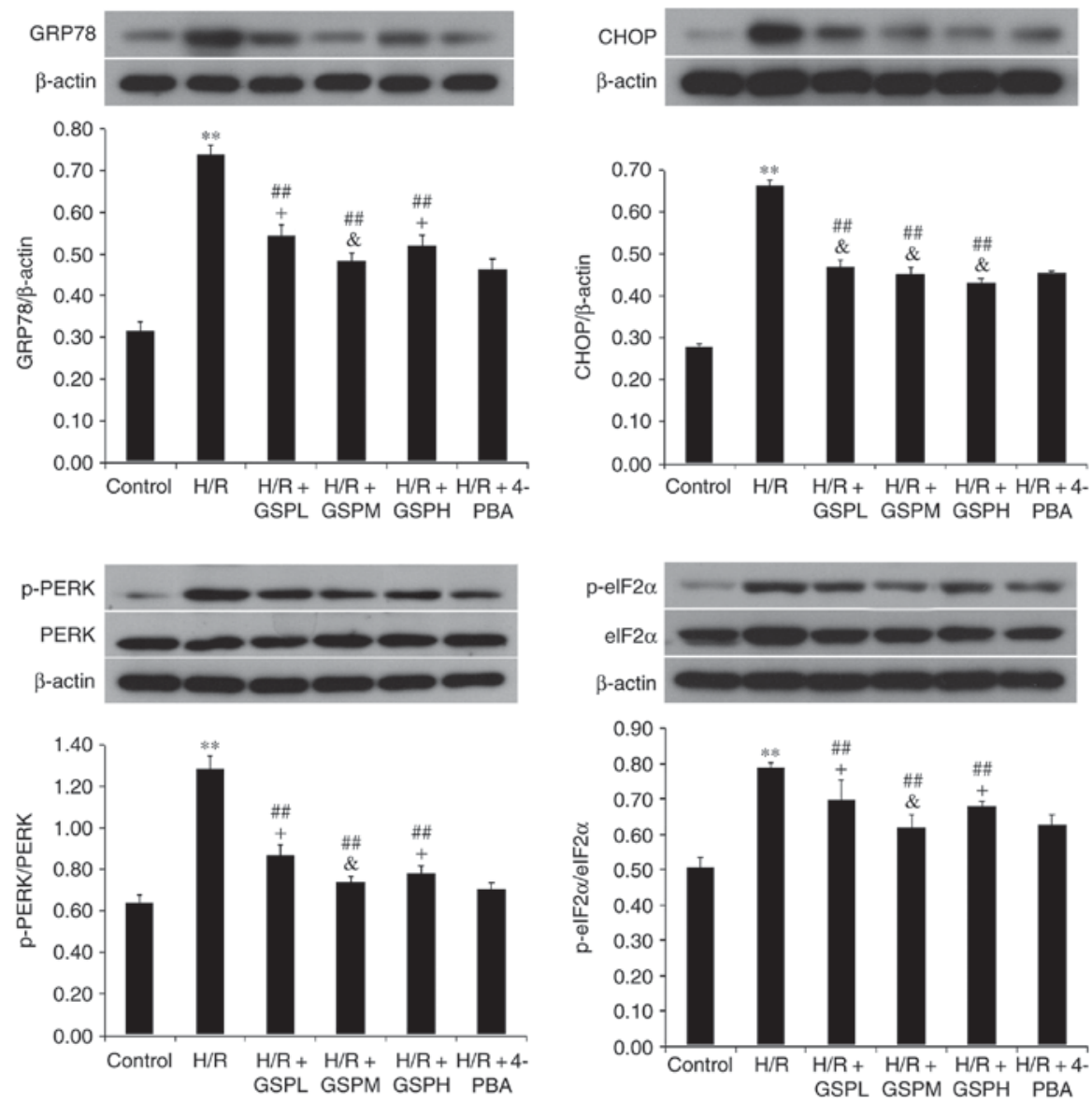

Figure 6. GSPs downregulated protein expression of GRP78, CHOP, p-PERK and p-eIF2 $\alpha$ in cardiomyocytes subjected to H/R. Representative immunoblots are represented above the quantitative bar graphs. p-PERK and p-eIF2 $\alpha$ were expressed as the ratio to total PERK and eIF2 $\alpha$. Data were represented as the mean \pm standard deviation; $n=3 .{ }^{* *} \mathrm{P}<0.01$ vs. the control group, ${ }^{\# \#} \mathrm{P}<0.01$ vs. the $\mathrm{H} / \mathrm{R}$ group, ${ }^{\text {\& }} \mathrm{P}>0.05$ and ${ }^{+} \mathrm{P}<0.05$ vs. the $\mathrm{H} / \mathrm{R}+4-\mathrm{PBA}$ group. $\mathrm{CHOP}$, C/EBP-homologous protein; eIF2 $\alpha$, eukaryotic translation initiation factor-2 $\alpha$; p-eIF2 $\alpha$, phosphorylated eIF2 $\alpha$; GPR78, glucose-regulated protein 78; GSP, grape seed proanthocyanidins; GSPL, GSP low (50 $\mu \mathrm{g} / \mathrm{ml})$; GSPM, GSP medium (100 $\mu \mathrm{g} / \mathrm{ml})$; GSPH, GSP high (200 $\mu \mathrm{g} / \mathrm{ml})$; H/R, hypoxia/reoxygenation; PERK, protein kinase RNA-like endoplasmic reticulum kinase; p-PERK, phosphorylated PERK; 4-PBA, 4-phenylbutyrate.

Prolonged ER stress may trigger ER stress-associated apoptosis pathways, including CHOP, JNK and caspase-12 pathways. Among them, CHOP, a downstream target of the PERK/eIF2 $\alpha$ pathway involved in the unfolded protein response (24), has a vital role in ER stress-mediated apoptosis (25). PERK activation responds to ER stress by autophosphorylation and then by phosphorylating the $\alpha$-subunit of eIF2 $\alpha$, which may subsequently trigger the CHOP signaling pathway (26).

To investigate how GSPs resist H/R-mediated injury, the expression levels of GRP78, CHOP, PERK and eIF2 $\alpha$ were measured. GRP78 is an ER chaperone response protein that is upregulated under ER stress. The high protein and mRNA expression of GRP78, eIF2 $\alpha$ and CHOP as well as increased protein expression of p-PERK in the H/R group revealed that ER stress and the activation of the PERK/eIF2 $\alpha$ pathway were induced by $\mathrm{H} / \mathrm{R}$. The significantly reduced expression levels in the GSPs treatment groups demonstrated that GSPs alleviated ER stress and blocked the PERK/eIF2 $\alpha$ pathway. Furthermore, GSPs were revealed as providing the same effect as 4-PBA in the inhibition of ER stress caused by H/R.

This study demonstrated that there was minimal change in the mRNA expression of PERK under the different experimental conditions, however, levels of p-PERK changed significantly and correlated with the protein expression levels of eIF $2 \alpha$ and CHOP. Therefore, the results indicated that GSPs may reduce the phosphorylation of PERK.

In response to an early prospective study that indicated that the polyphenol fraction of proanthocyanidins in red wine have a beneficial effect with regards to the prevention of coronary disease (27), GSPs have become a prevalent research focus worldwide. Although lycopene and astaxanthin possess a greater anti-oxidative ability compared to that of proanthocyanidins, their in vivo potential is limited by their lipid-soluble nature. On the other hand, proanthocyanidins are water-soluble and act in systemic fluid, which determines them as the most powerful antioxidant applicable in medical and nutrition fields.

Several studies have demonstrated various biological activities of proanthocyanidins, however, there is inadequate research linking proanthocyanidins to their protective abilities against myocardial I/R injury. Sato et al (28) reported that GSPs effectively decreased the extent of myocardial infarction in rats via scavenging of peroxyl and hydroxyl radicals for the attenuation of oxidative stress following I/R. Additionally, a previous study reported that GSPs may prevent ventricular tachycardia and fibrillation induced by reperfusion through the scavenging of free radicals in isolated rat hearts (29). 
Zhao et al (30) further demonstrated that the upregulation of the $\mathrm{Na}^{+} / \mathrm{K}^{+}$-ATPase $\alpha$-subunit may be responsible for the protective effect of GSPs on reperfusion arrhythmias in rats in vivo. Another pathway involving GSPs for the prevention from myocardial I/R injury is its effect on reducing intracellular $\mathrm{Ca}^{2+}$ concentrations (29). Shao et al (31) demonstrated that GSPs increased nitric oxide production, mediated by the Akt-endothelial nitric oxide synthase signaling pathway, to offer cardioprotection against H/R injury on cardiomyocytes. The literature, therefore, suggests that GSPs have an effect of anti-myocardial I/R injury. Previous studies also reported the protective effect of GSPs against I/R injury in the liver, brain, intestine and kidney (32-35). However, its protection against cardiomyocyte apoptosis and underlying mechanisms associated with ER stress are unknown. This study, to the best of our knowledge, was the first to demonstrate that GSPs can attenuate H/R-induced cardiomyocyte injury by inhibiting ER stress-dependent apoptosis through suppressed activation of the PERK/eIF2 $\alpha$ pathway.

This study explored, for the first time, the protective effects and inhibitory levels of ER stress among different administered concentrations of GSPs in H/R cardiomyocytes. It was confirmed that a higher GSPs concentration did not provide a greater protective effect and instead may have been harmful to cardiomyocytes. Additionally, to the best of our knowledge, the study was the first to propose that GSPs exert protective effects on H/R cardiomyocytes by blocking both the ER stress upstream PERK/eIF2 $\alpha$ pathway and CHOP apoptosis pathway to decrease cell apoptosis.

A potential limitation of of this study was that $\mathrm{H} 9 \mathrm{C} 2$ cardiomyocytes do not undergo spontaneous contraction so they may not fully represent human cardiomyocytes. An animal model should be established to further support the results of this study.

\section{Acknowledgements}

The present study was supported by the First Affiliated Hospital of China Medical University (Shenyang, China).

\section{References}

1. Garcia-Dorado D: Myocardial reperfusion injury: A new view. Cardiovasc Res 61: 363-364, 2004.

2. Sharma V, Bell RM and Yellon DM: Targeting reperfusion injury in acute myocardial infarction: A review of reperfusion injury pharmacotherapy. Expert Opin Pharmacother 13: 1153-1175, 2012

3. Bainey KR and Armstrong PW: Clinical perspectives on reperfusion injury in acute myocardial infarction. Am Heart J 167: 637-645, 2014.

4. Murry CE, Jennings RB and Reimer KA: Preconditioning with ischemia: A delay of lethal cell injury in ischemic myocardium. Circulation 74: 1124-1136, 1986.

5. Zhao ZQ, Corvera JS, Halkos ME, Kerendi F, Wang NP, Guyton RA and Vinten-Johansen J: Inhibition of myocardial injury by ischemic postconditioning during reperfusion: Comparison with ischemic preconditioning. Am J Physiol Heart Circ Physiol 285: H579-H588, 2003.

6. Kalogeris T, Baines CP, Krenz M and Korthuis RJ: Cell biology of ischemia/reperfusion injury. Int Rev Cell Mol Biol 298: 229-317, 2012.

7. Stamboul K, Lorin J, Lorgis L, Guenancia C, Beer JC, Touzery C, Rochette L, Vergely C, Cottin Y and Zeller M: Atrial fibrillation is associated with a marker of endothelial function and oxidative stress in patients with acute myocardial infarction. PLoS One 10: e0131439, 2015.
8. Logue SE, Cleary P, Saveljeva S and Samali A: New directions in ER stress-induced cell death. Apoptosis 18: 537-546, 2013.

9. Doroudgar S and Glembotski CC: New concepts of endoplasmic reticulum function in the heart: Programmed to conserve. J Mol Cell Cardiol 55: 85-91, 2013.

10. Schroder M and Kaufman RJ: The mammalian unfolded protein response. Annu Rev Biochem 74: 739-789, 2005.

11. Tabas I and Ron D: Integrating the mechanisms of apoptosis induced by endoplasmic reticulum stress. Nat Cell Biol 13: 184-190, 2011.

12. Boyce M and Yuan J: Cellular response to endoplasmic reticulum stress: A matter of life or death. Cell Death Differ 13: 363-373, 2006.

13. Kasseckert SA, Schäfer C, Kluger A, Gligorievski D, Tillmann J, Schlüter KD, Noll T, Sauer H, Piper HM and Abdallah Y: Stimulation of cGMP signalling protects coronary endothelium against reperfusion-induced intercellular gap formation. Cardiovasc Res 83: 381-387, 2009.

14. Bagchi D, Bagchi M, Stohs Sj, Ray SD, Sen CK and Preuss HG: Cellular protection with proanthocyanidins derived from grape seeds. Ann N Y Acad Sci 957: 260-270, 2002.

15. Kim TH, Jeon EJ, Cheung DY, Kim CW, Kim SS, Park SH, Han SW, Kim MJ, Lee YS, Cho ML, et al: Gastroprotective effects of grape seed proanthocyanidin extracts against nonsteroid anti-inflammatory drug-induced gastric injury in rats. Gut Liver 7: 282-289, 2013.

16. Ozkan G, Ulusoy S, Alkanat M, Orem A, Akcan B, Ersöz S, Yulu $\breve{g}$ E, Kaynar K and Al S: Antiapoptotic and antioxidant effects of GSPE in preventing cyclosporine A-induced cardiotoxicity. Ren Fail 34: 460-466, 2012.

17. Singh T, Sharma SD and Katiyar SK: Grape proanthocyanidins induce apoptosis by loss of mitochondrial membrane potential of human non-small cell lung cancer cells in vitro and in vivo. PLoS One 6: e27444, 2011.

18. Cheng M, Gao HQ, Xu L, Li BY, Zhang H and Li XH: Cardioprotective effects of grape seed proanthocyanidins extracts in streptozocin induced diabetic rats. J Cardiovasc Pharmacol 50: 503-509, 2007.

19. Gao Y, Jia P, Shu W and Jia D: The protective effect of lycopene on hypoxia/reoxygenation-induced endoplasmic reticulum stress in H9C2 cardiomyocytes. Eur J Pharmacol 774: 71-79, 2016.

20. Livak KJ and Schmittgen TD: Analysis of relative gene expression data using real-time quantitative PCR and the 2(-Delta Delta C(T)) method. Methods 25: 402-408, 2001.

21. Sun J, Sun G, Meng X, Wang H, Wang M, Qin M, Ma B, Luo Y, Yu Y, Chen R, et al: Ginsenoside RK3 prevents hypoxia-reoxygenation induced apoptosis in $\mathrm{H} 9 \mathrm{c} 2$ cardiomyocytes via AKT and MAPK pathway. Evid Based Complement Alternat Med 2013: 690190, 2013

22. Yang Y, Duan W, Jin Z, Yi W, Yan J, Zhang S, Wang N, Liang Z, Li Y, Chen W, et al: JAK2/STAT3 activation by melatonin attenuates the mitochondrial oxidative damage induced by myocardial ischemia/reperfusion injury. J Pineal Res 55: 275-286, 2013.

23. Hou X, Han J, Yuan C, Ren H, Zhang Y, Zhang T, Xu L, Zheng Q and Chen W: Cardioprotective effects of total flavonoids extracted from xinjiang sprig rosa rugosa against acute ischemia/reperfusion-induced myocardial injury in isolated rat heart. Cardiovasc Toxicol 16: 54-66, 2016.

24. Marklund S and Marklund G: Involvement of the superoxide anion radical in the autoxidation of pyrogallol and a convenient assay for superoxide dismutase. Eur J Biochem 47: 469-474, 1974

25. van Huizen R, Martindale JL, Gorospe M and Holbrook NJ: P58IPK, a novel endoplasmic reticulum stress-inducible protein and potential negative regulator of eIF2alpha signaling. J Biol Chem 278: 15558-15564, 2003.

26. Ron D and Walter P: Signal integration in the endoplasmic reticulum unfolded protein response. Nat Rev Mol Cell Biol 8: 519-529, 2007.

27. Rimm EB, Giovannucci EL, Willett WC, Colditz GA, Ascherio A, Rosner B and Stampfer MJ: Prospective study of alcohol consumption and risk of coronary disease in men. Lancet 338: 464-468, 1991.

28. Sato M, Maulik G, Ray PS, Bagchi D and Das DK: Cardioprotective effects of grape seed proanthocyanidin against ischemic reperfusion injury. J Mol Cell Cardiol 31: 1289-1297, 1999.

29. Pataki T, Bak I, Kovacs P, Bagchi D, Das DK and Tosaki A: Grape seed proanthocyanidins improved cardiac recovery during reperfusion after ischemia in isolated rat hearts. Am J Clin Nutr 75: 894-899, 2002. 
30. Zhao G, Gao H, Qiu J, Lu W and Wei X: The molecular mechanism of protective effects of grape seed proanthocyanidin extract on reperfusion arrhythmias in rats in vivo. Biol Pharm Bull 33: 759-767, 2010.

31. Shao ZH, Wojcik KR, Dossumbekova A, Hsu C, Mehendale SR, Li CQ, Qin Y, Sharp WW, Chang WT, Hamann KJ, et al: Grape seed proanthocyanidins protect cardiomyocytes from ischemia and reperfusion injury via Akt-NOS signaling. J Cell Biochem 107: 697-705, 2009.

32. Gao Z, Liu G, Hu Z, Li X, Yang X, Jiang B and Li X: Grape seed proanthocyanidin extract protects from cisplatin-induced nephrotoxicity by inhibiting endoplasmic reticulum stress-induced apoptosis. Mol Med Rep 9: 801-807, 2014.
33. Liu CM, Ma JQ, Liu SS, Zheng GH, Feng ZJ and Sun JM: Proanthocyanidins improves lead-induced cognitive impairments by blocking endoplasmic reticulum stress and nuclear factor- $\kappa \mathrm{B}-$ mediated inflammatory pathways in rats. Food Chem Toxicol 72: 295-302, 2014.

34. Sizlan A, Guven A, Uysal B, Yanarates O, Atim A, Oztas E, Cosar A and Korkmaz A: Proanthocyanidin protects intestine and remote organs against mesenteric ischemia/reperfusion injury. World J Surg 33: 1384-1391, 2009.

35. Xu ZC, Yin J, Zhou B, Liu YT, Yu Y and Li GQ: Grape seed proanthocyanidin protects liver against ischemia/reperfusion injury by attenuating endoplasmic reticulum stress. World J Gastroenterol 21: 7468-7477, 2015. 